\author{
Pathophysiology \\ Haemostasis \\ and Thrombosis
}

\title{
New Aspects in Thrombotic Research: Complement Induced Switch in Mast Cells from a Profibrinolytic to a Prothrombotic Phenotype
}

\author{
Johann Wojtaa, Kurt Huberb, Peter Valentc \\ aDepartment of Internal Medicine II, Medical University Vienna, Austria \\ b3rd Medical Department for Cardiology and Emergency Medicine, Wilheminenspital, Vienna, Austria \\ cDepartment of Internal Medicine I, Division of Hematology \& Hemostaseology, Medical University Vienna, Austria
}

\section{Key Words}

Mast cells · Thrombosis · Complement · Plasminogen activation

\begin{abstract}
Mast cells, strategically located in the vicinity of blood vessels, are multifunctional effector cells participating in the modulation of various inflammatory and cardiovascular disease processes by actively releasing a wide variety of vasoactive mediators. These cells have also been implicated in the regulation of thrombosis and the development and progression of atherosclerosis. By expressing enzymatically active tissue typeplasminogen activator (t-PA), human mast cells (MC) might play a role in endogenous fibrinolysis and extracellular matrix remodelling - both processes that are essential in the pathogenesis of cardiovascular disorders. However, when treated with the anaphylotoxin C5a, mast cells express the PA inhibitor 1 (PAI-1) in excess over t-PA. In context with studies suggesting a role for mast cells and components of the complement system in the development of cardiovascular disease our results lead to the hypothesis that mast cells by producing t-PA in a resting state and by expressing PAI-1 when activated by C5a might participate in the modulation of the balance between proteases and pro-
\end{abstract}

\section{KARGER}

Fax +41613061234

E-Mail: karger@karger.ch

www.karger.com
(C) 2004 S. Karger AG, Basel

$1424-8832 / 04 / 0336-0438 \$ 21.0 / 0$

Accessible online at: www.krager.com/pht tease inhibitors regulating tissue injury and repair in these disease processes. In addition, C5a might upregulate PAI- 1 in mast cells to prevent its own inactivation by plasmin in an autocrine or paracrine fashion.

Copyright (C) 2004 S. Karger AG, Basel

\section{Introduction}

Mast cells are multifunctional effector cells, which are involved in a variety of physiological and pathophysiological events [1]. They can be detected in most organ systems and are located in loose connective tissue in next vicinity to blood vessels and nerves. By producing and releasing a variety of vasoactive mediators such as histamine, heparin, prostaglandin D2, vascular endothelial growth factor (VEGF), tryptase, chymase and cytokines such as tumor necrosis factor-alpha (TNF- $\alpha$ ), mast cells are considered to contribute to the modulation of vasodilation, edema and capillary leakage-formation, angiogenesis, leukocyte migration and endothelial cell activation [2].

\section{Mast Cells and Cardiovascular Disease}

\section{Mast Cells and Thrombosis}

It has been shown in several studies that the number of mast cells increases in venous thrombosis, whereby in deep venous thrombosis mast cells accumulate in vicinity to the

Johann Wojta Ph.D.

Department of Internal Medicine II

Medical University Vienna

Waehringer Guertel 18-20,

A-1090 Vienna, Austria

Tel: +43 1 404002247; Fax: +431 404004216;

E-mail: johann.wojta@meduniwien.ac.at 
vasa vasorum at the site of the thrombus [3]. In auricular thrombosis mast cells are found in the upper endocardium. Mast cell accumulation has also been described in liver vein thrombosis and pulmonary embolism [3-5]. It has also been shown that mast cell deficient mice have an increased risk to develop fatal thrombosis [6]. Mast cell reconstitution in these mice by bone marrow transplantation resulted in protection from these events. In the same model heparin had a similar protective effect [6]. Thus it seems likely that mast cells might play a role in the repair processes after thrombus formation and/or in the prevention of thrombosis, probably via the production of heparin and tissue type plasminogen activator (t-PA; see also below).

\section{Mast Cells and Atherosclerosis}

A role for mast cells in the development and progression of atherosclerosis has also been proposed recently. This hypothesis is based on observations showing that the number of degranulated mast cells in the adventitia next to ruptured atherosclerotic plaques is increased [7]. In that respect it is also of interest that mast cells produce metalloproteinase-2 (MMP-2) and MMP-9 - proteases critically involved in the destabilization of plaques - when activated with kit ligand or transforming growth factor-beta or when in contact with activated T cells $[8,9]$. In addition it could be demonstrated that other MMPs participating in plaque destabilization such as MMP-1 and MMP-3 can be activated from their respective inactive proenzyme by mast cellderived tryptase and chymase [10]. Furthermore, mast cells can connect with sensory nerve fibers in atherosclerotic coronary arteries which raises the possibility that upon neurogenic stimulation these cells may release mediators such as histamine and leukotrienes which then in turn contribute to the complex neurohumoral response that leads to pathological coronary vasoconstriction [11].

\section{Components of the Complement System and Cardiovascular Disease}

Activation of the complement cascade is a major aspect of chronic inflammatory diseases. Such activation - among other effects - might also result in vascular injury. This notion has been supported by the observation that components of the complement cascade have been found in atherosclerotic plaques in the vessel wall [12]. By activating mast cells and other leukocytes, components of the complement system may contribute to inflammatory processes within the vascular wall and as such might be involved in the development and progression of disease processes such as atherosclerosis. In that respect it should be emphasized that the

Complement Induced Switch in Mast Cells from a

Profibrinolytic to a Prothrombotic Phenotype
C5a inhibitor pexelizumab reduces mortality in patients undergoing coronary artery bypass surgery or receiving reperfusion therapy after acute myocardial infarction [13]. Furthermore, markers of inflammation predicting mortality are reduced by pexelizumab in patients suffering from acute myocardial infarction [14]. In addition, complement peptides such as C3a and C5a have been shown to stimulate chemotaxis of mast cells and to induce the release of mediators such as histamine and leukotrienes from these cells $[15,16]$. Thus, it is tempting to speculate that components of the complement system by activating mast cells could contribute to their role in the development of cardiovascular diseases as described above.

\section{Mast Cells as Modulators of the Plasminogen Activator/Plasmin System}

The plasminogen activator (PA)/plasmin system is involved in a multitude of physiological and pathophysiological processes such as clot lysis, ovulation, cell migration, wound healing, angiogenesis, tumor growth and metastasis and embryonic development [17]. The central enzyme in this system is plasmin, which is activated from its inactive proenzyme plasminogen by two PAs, namely t-PA and urokinase type-PA (u-PA). The activity of these two serine proteases is regulated by their physiologic inhibitors PA inihibitor-1 (PAI-1), PAI-2 and protein C inhibitor (PCI) or PAI-3, all members of the serine protease inhibitor (serpin) family [17]. These inhibitors neutralize the enzymatic activities of u-PA and t-PA by complex formation. We have recently shown that resting mast cells express t-PA constitutively without simultaneously producing PAIs [18]. This in contrast to other (peri)vascular cell types involved in fibrinolysis such as endothelial cells, smooth muscle cells, or macrophages. At least in vitro these cells produce significant levels of PAIs sufficient to neutralize the enzymatic activity of the coproduced PAs [19-21]. Because of the lack of PAI production by resting mast cells the secreted t-PA is enzymatically active and thus is able to activate plasminogen into the active enzyme plasmin. Therefore, we believe that resting mast cells by producing active t-PA play a major role in endogenous fibrinolysis by regulating repair processes after thrombus formation and/or the prevention of thrombosis. Since plasmin cannot only degrade fibrin but can also activate MMPs from inactive pro-MMPs one could speculate that via this mechanism mast cells could also be involved in the remodelling or degradation of extracellular matrix by these enzymes and as such play a role in the destabilization of atherosclerotic plaques [22].

More recently it has been shown that mast cells produce appreciable amounts of PAI-1 when incubated with PMA or

Pathophysiol Haemost Thromb 2003/2004;33:438-441 
A) Resting Mast Cell

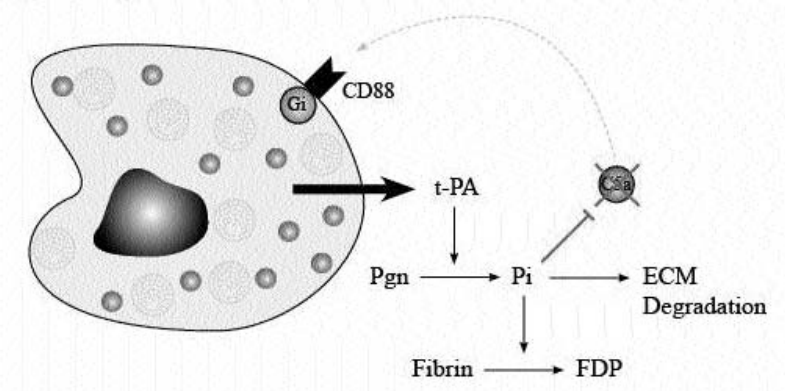

B) C5a activated Mast Cell

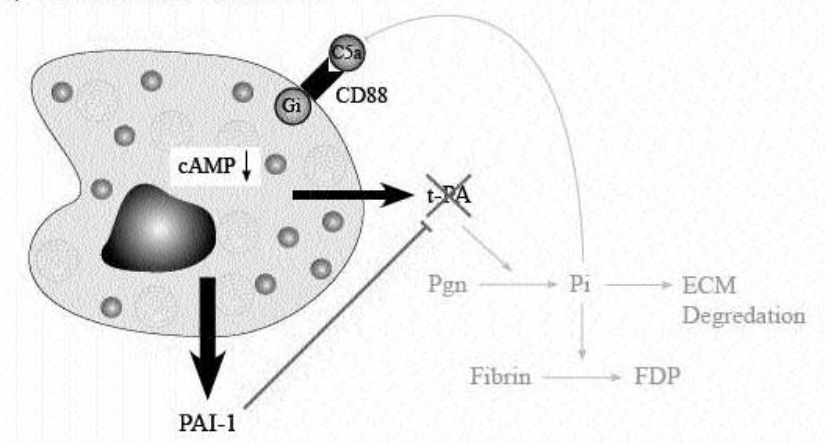

Fig. 1. Schematic representation of a resting mast cell (panel A) and a mast cell activated by C5a (panel B). Black: active pathways; grey: inactive pathways; abbreviations: cAMP: cyclic adenosine monophosphate; CD88: C5a receptor; ECM: extracellular matrix; FDP: fibrin degradation products; Gi: inhibitory G-protein; PAI-1 plasminogen activator inhibitor1; Pgn: plasminogen; Pi: plasmin; t-PA: tissue type-plasminogen activator

calcium ionophore. PAI-1 was also found in lung mast cells in a patient with asthma attack [23]. The authors of this study proposed a role for mast cell-derived PAI-1 in airway remodelling in asthma. We have recently identified C5a as a physiologic mediator of PAI-1 expression in human mast cells [24]. When treated with C5a human mast cells secret PAI-1 in excess over t-PA. Therefore, in such cells t-PA is completely complexed and thus neutralized by simultane- ously secreted PAI-1 and a surplus of enzymatically active PAI-1 is found. Thus the profibrinolytic, antithrombotic resting mast cell producing active t-PA in the absence of PAI-1 has changed into an antifibrinolytic, prothrombotic phenotype secreting PAI-1 in excess over t-PA under the influence of C5a. In this regard it is noteworthy that many other mediators and cytokines do not induce PAI-1 expression in human mast cells suggesting a unique effect for C5a. Based on all these observations we speculate that apart from their profibrinolytic properties in the resting state mast cells could - by expressing PAI-1 under distinct, C5a -dependent conditions such as chronic inflammatory processes in cardiovascular disease - participate in the modulation of the balance between proteases and protease inhibitors that regulates tissue injury and repair in these disease states. Finally it should also be mentioned that C5a is sensitive to cleavage and inactivation by plasmin [25]. In this context it is tempting to speculate that C5a upregulates the expression of PAI1 in mast cells to prevent its own inactivation. In such an autocrine or paracrine loop PAI-1 produced by mast cells in response to activation by C5a would inactivate t-PA produced by these cells, which in turn would prevent plasmin formation and thus inactivation of C5a by plasmin (Figure 1).

\section{Concluding Remarks}

In addition to the multitude of functions exerted by mast cells in the modulation of various physiological and pathophysiological processes recent data strongly suggest that mast cells also play a key role in the regulation of the $\mathrm{PA} /$ plasmin system. In a resting state the mast cell - at least to our knowledge - represents the only (peri)vascular cell type secreting active t-PA. In this state mast cells are profibrinolytic and antithrombotic and could be essential for thrombus dissolution but also for extracellular matrix degradation. In diseases processes involving chronic inflammation with complement activation, the anaphylotoxin C5a can induce a switch in mast cells to an antifibrinolytic, prothrombotic phenotype that would inhibit fibrinolysis and extracellular proteolysis.

\section{References}

1 Galli SJ. Mast cells and basophils. Curr Opin Hematol 2000;7:32-39.

$\checkmark 2$ Valent P. Cytokines involved in growth and differentiation of human basophils and mast cells. Exp Dermatol 1995;4:255-259.

3 Valent P, Sillaber C, Baghestanian M, Bankl HC, Kiener HP, Lechner K, Binder BR. What have mast cells to do with edema formation, the consecutive repair and fibrinolysis? Int Arch Allergy Immunol 1998;115:2-8.
Bankl HC, Radaszkiewicz T, Klappacher GW, Glogar D, Sperr WR, Grossschmidt K, Bankl H, Lechner K, Valent P. Increase and redistribution of cardiac mast cells in auricular thrombosis. Possible role of kit ligand. Circulation 1995;91:275-283.

5 Valent P, Baghestanian M, Bankl HC, Sillaber C, Sperr WR, Wojta J, Binder BR, Lechner K. New aspects in thrombosis research: possible role of mast cells as profibrinolytic and antithrombotic cells. Thromb Haemost 2002;87:786-790.

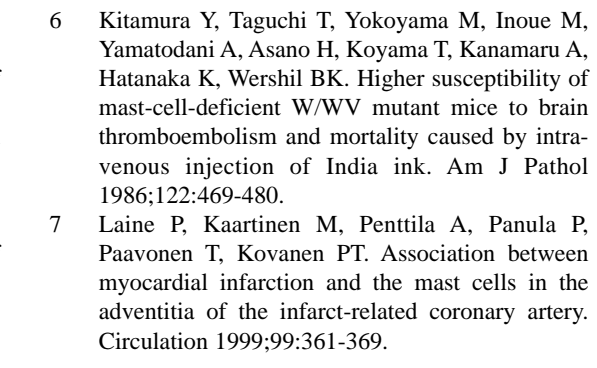

Wojta/Huber/Valent 
8 Fang KC, Wolters PJ, Steinhoff M, Bidgol A, Blount JL, Caughey GH. Mast cell expression of gelatinases $\mathrm{A}$ and $\mathrm{B}$ is regulated by kit ligand and TGF-beta. J Immunol 1999;162:5528-5535.

$\checkmark$ Baram D, Vaday GG, Salamon P, Drucker I, Hershkoviz R, Mekori YA. Human mast cells release metalloproteinase-9 on contact with activated T cells: juxtacrine regulation by TNF-alpha. J Immunol 2001;167:4008-4016.

10 Johnson JL, Jackson CL, Angelini GD, George SJ. Activation of matrix-degrading metalloproteinases by mast cell proteases in atherosclerotic plaques. Arterioscler Thromb Vasc Biol 1998;18:17071715.

11 Laine P, Naukkarinen A, Heikkila L, Penttila A, Kovanen PT. Adventitial mast cells connect with sensory nerve fibers in atherosclerotic coronary arteries. Circulation 2000;101:1665-1669.

12 Yasojima K, Schwab C, McGeer EG, McGeer PL. Complement components, but not complement inhibitors, are upregulated in atherosclerotic plaques. Arterioscler Thromb Vasc Biol 2001;21: 1214-1219.

13 Verrier ED, Shernan SK, Taylor KM, Van de Werf F, Newman MF, Chen JC, Carrier M, Haverich A, Malloy KJ, Adams PX, Todaro TG, Mojcik CF, Rollins SA, Levy JH, PRIMO-CABG Investigators. Terminal complement blockade with pexelizumab during coronary artery bypass graft surgery requiring cardiopulmonary bypass: a randomized trial. JAMA 2004;291:2319-2327.
14 Granger CB, Mahaffey KW, Weaver WD, Theroux P, Hochman JS, Filloon TG, Rollins S, Todaro TG Nicolau JC, Ruzyllo W, Armstrong PW; COMMA Investigators. Pexelizumab, an anti-C5 complement antibody, as adjunctive therapy to primary percutaneous coronary intervention in acute myocardial infarction: the COMplement inhibition in Myocardial infarction treated with Angioplasty (COMMA) trial. Circulation 2003;108:1184-1190.

15 Hartmann K, Henz BM, Kruger-Krasagakes S, Kohl J, Burger R, Guhl S, Haase I, Lippert U, Zuberbier T. C3a and C5a stimulate chemotaxis of human mast cells. Blood 1997;89:2863-2870.

16 el-Lati SG, Dahinden CA, Church MK. Complement peptides C3a- and C5a-induced mediator release from dissociated human skin mast cells. J Invest Dermatol 1994;102:803-806.

17 Collen D. Ham-Wasserman lecture: role of the plasminogen system in fibrin-homeostasis and tissue remodeling. Hematology (Am Soc Hematol Educ Program). 2001:1-9.

18 Sillaber C, Baghestanian M, Bevec D, Willheim M, Agis H, Kapiotis S, Fureder W, Bankl HC, Kiener HP, Speiser W, Binder BR, Lechner K, Valent $P$. The mast cell as site of tissue-type plasminogen activator expression and fibrinolysis $\mathrm{J}$ Immunol 1999;162:1032-1041.

19 van Hinsbergh VW. The endothelium: vascular control of haemostasis. Eur J Obstet Gynecol Reprod Biol. 2001;95:198-201.
20 Loskutoff DJ, Sawdey M, Keeton M, Schneiderman J. Regulation of PAI-1 gene expression in vivo. Thromb Haemost 1993;70:135-137.

21 Wojta J, Gallicchio M, Zoellner H, Hufnagl P, Last K, Filonzi EL, Binder BR, Hamilton JA, McGrath K. Thrombin stimulates expression of tissue-type plasminogen activator and plasminogen activator inhibitor type 1 in cultured human vascular smooth muscle cells. Thromb Haemost 1993;70:469-474.

22 Libby P. Vascular biology of atherosclerosis: overview and state of the art. Am J Cardiol 2003;91:3A-6A.

23 Cho SH, Tam SW, Demissie-Sanders S, Filler SA, Oh CK. Production of plasminogen activator inhibitor- 1 by human mast cells and its possible role in asthma. J Immunol 2000;165:3154-3161.

24 Wojta J, Kaun C, Zorn G, Ghannadan M, Hauswirth AW, Sperr WR, Fritsch G, Printz D, Binder BR, Schatzl G, Zwirner J, Maurer G, Huber $\mathrm{K}$, Valent P. C5a stimulates production of plasminogen activator inhibitor-1 in human mast cells and basophils. Blood 2002;100:517-523.

25 Higazi A al-R, Barghouti II. Inactivation of human anaphylatoxin C5a and C5a des-Arg through cleavage by the plasminogen activator activity of a human fibrosarcoma cell line. J Biol Chem 1994;269:25529-25533. 